\title{
Managing water in the city of the future; strategic planning and science
}

\author{
Peter van der Steen · Carol Howe
}

Published online: 24 April 2009

(C) Springer Science+Business Media B.V. 2009

\section{Introduction}

Increasing global change pressures, escalating costs and other risks inherent to conventional urban water management are causing cities to face ever increasing difficulties in efficiently managing scarcer and less reliable water resources.

In order to meet these challenges SWITCH (Sustainable Water Management Improves Tomorrow's Cities Health) is facilitating a paradigm shift in urban water management. SWITCH is an EU funded action research program being implemented and cofunded by a cross-disciplinary team of 33 partners from across the globe, including 17 from the EU and 12 from developing countries. The "consortium" comprises the academic and urban planning fields, water utilities and consultants. This network of researchers and practitioners are working directly with stakeholders in ten cities (see Fig. 1). The overall goal behind this global consortium is to catalyse change towards more sustainable urban water management in the "City of the Future". Demonstrating research and sharing knowledge across a range of different geographical, climatic and socio-cultural settings is expected to lead to

P. van der Steen $(\bowtie) \cdot C$. Howe

UNESCO-IHE Institute for Water Education, Department

of Environmental Resources, PO Box 3015, 2601 DA

Delft, The Netherlands

e-mail: p.vandersteen@unesco-ihe.org

URL: www.switchurbanwater.eu global adoption and acceleration of more sustainable solutions.

The SWITCH research process is a combination of:

- Learning Alliances-SWITCH is linking up a wide range of stakeholders at city level to interact productively and to create win-win solutions along the water chain. They consist of a series of structured platforms, at different institutional levels (national, river basin, city, community etc.), designed to break down barriers to both horizontal and vertical information sharing thereby speeding up the process of identification, adaptation, and uptake of new innovations. LA's have been established in Accra, Alexandria, Beijing, Belo Horzionte, Birmingham, Cali, Hamburg, Lima, Lodz, Tel Aviv and Zaragoza.

- Action Research-SWITCH is carrying out more demand-led, action-orientated research in cities with a view to achieving greater integration and wider impact through the Learning Alliances.

- Multiple-way learning-SWITCH is promoting multiple-way learning, where European cities learn from each other and from developing countries, and vice versa.

\section{Strategic planning and scientific assessment of strategies}

One goal of SWITCH is to develop new strategic plans for water management in the cities mentioned 


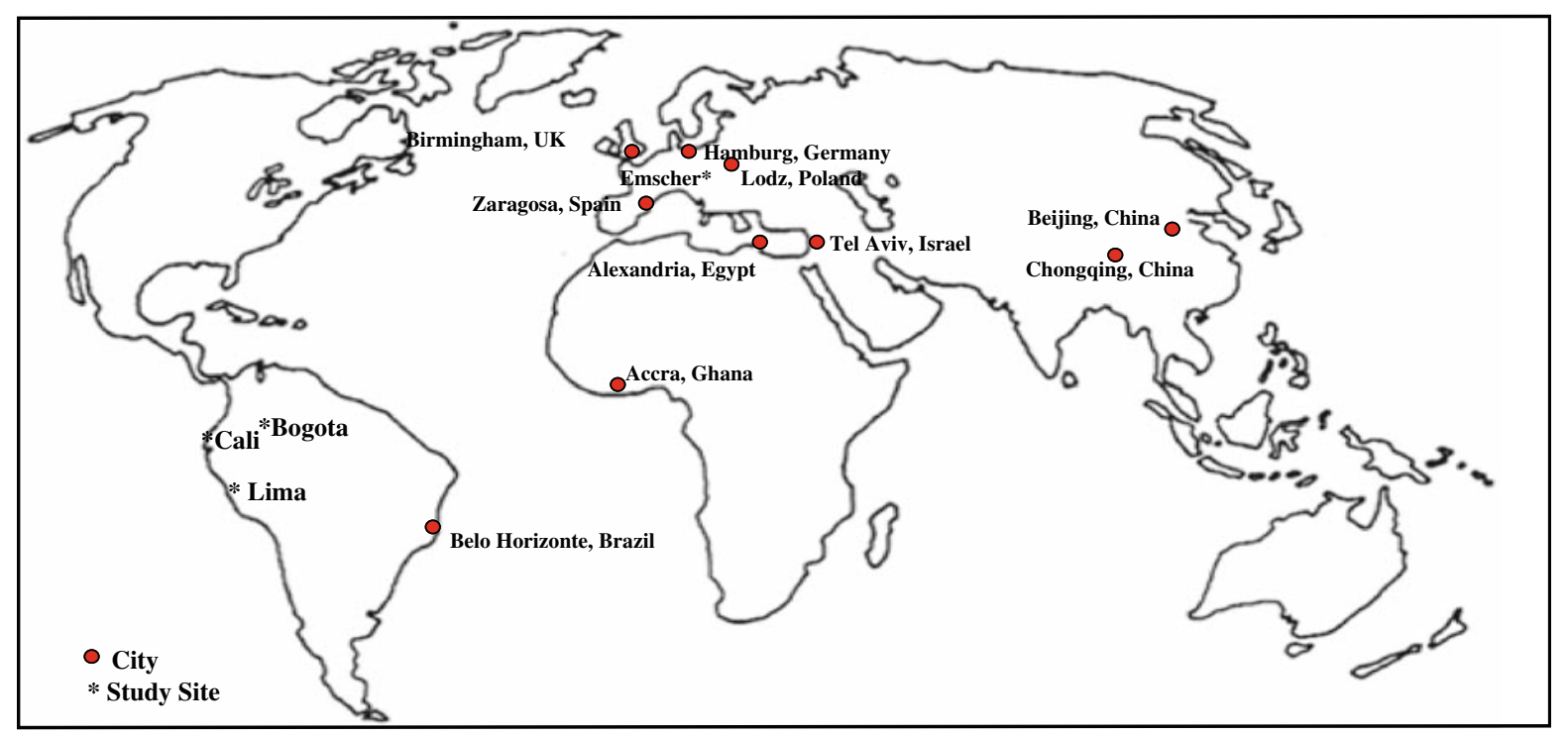

Fig. 1 SWITCH cities and study sites

above. These strategic plans are developed by the LA (Learning Alliance) and are based on the inclusion of scientific innovations, both in the technical as well as in the socio-economic field. Scientific assessment methodologies, such as Mass Flow Analysis, Water Balance studies and Energy footprints, are used to evaluate the new strategies.

New strategies for urban water management are needed because in many cities, not only in the developing world, the objectives of urban water management are not fully met. Sustainable Urban Water Management is to serve urban dwellers with reliable water services, without compromising the integrity of the environmental resources that are sustaining these services. The institutions that are delivering the services, or managing the urban water system, base their actions on a certain 'approach'. This approach to managing the city or its water system is usually found in mission statements or strategic planning documents. Sometimes the approach is not made explicit, but nevertheless directs the actions of the organization. It is believed by many researchers (and indeed one of the assumptions of the SWITCH project) that the underlying approaches should be modified in order to result in more effective and efficient management actions, and ultimately in a sustainable urban water system. In order to develop the new approach, case studies are undertaken in the cities mentioned above. The case studies are designed to contribute to the testing of the following hypothesis:

\section{Design and management of the urban water system based on an analysis and optimisation of the entire urban water syste (infrastructure and human organisations, water supply, sanitation, stormwater etc.) will lead to more sustainable solutions than optimisation of separate elements of the system.}

The hypothesis is tested based on the results from research and demonstration activities in the various cities. Not only on the basis of theoretical considerations, but also based on practice in the cities. If the hypothesis is found to be true and of practical value, than it is a strong encouragement to modify the design, planning and management of the urban water system. For example, one should then formulate general sustainability objectives for the entire system, rather than for an element (for instance the water distribution network, or the wastewater treatment plant). Equally, one would formulate indicators that measure the state of the entire system, rather than performance indicators that measure the functioning of a subsystem, or performance indicators for an organization that manages a subsystem. Monitoring the value of general sustainability indicators for the entire system will give an indication to policy and decision makers whether the city is moving towards 
or away from sustainability (economy, environment, society). Based on the indicators score, the policies and strategies are then adapted.

\section{Systems engineering}

One of the new approaches advocated in the water sector (Mitchell 2004; UNESCO 2007) is 'Integrated Urban Water Management' (IUWM). There is so far no generally accepted definition of this term. It is proposed here that IUWM can be interpreted as the application of systems analyis and systems engineering to the urban water system. A system is defined as 'a collection of various structural and non-structural (e.g., human) elements which are interconnected and organized in such a way as to achieve some specified objective by the control and distribution of material resources, energy and information' (Smith et al. 1987). For the water system the objective is to create or maintain a safe and clean environment and to deliver water and sanitation services to the urban population. Resources that are used to achieve this objective are construction materials for the various infrastructure components, as well as chemicals, energy and water to run the system.

Systems engineering aims to design systems that are more efficient and effective in reaching the objective as a system, than the individual component would be able to achieve if designed and operated in isolation (Smith et al. 1987). The application of this general statement to the urban water system is the major hypothesis of SWITCH mentioned above. This means that the water resource system (rivers, groundwater), the water treatment and distribution network, the stormwater network, the wastewater collection and treatment system, should be designed and operated as one system. Practice in most cities in the world show that this is not generally the case. Analysis of the approach to urban water management in the SWITCH demonstration cities shows that water management is often carried out in a rather fragmented way. To overcome this institutional fragmentation is a matter of cooperation, political willingness, joint design, information exchange, willingness to share and learn, etc. Institutional boundaries are related to the boundaries of the system that is under analysis. Just like inter or intra-institutional cooperation is important, it is crucial that system boundaries are wide enough, not to externalize important effects, either in space or time. Too narrow system boundaries will result in 'harmful suboptimization' (Hellström et al. 2000).

Systems engineering stresses that both structural and human elements are part of the system. If systems engineering is accepted as an approach in urban planning, it follows naturally that definition of objectives is always a contested and never an obvious exercise. The human element, in its various organization forms, is an integral element of the system and therefore each stakeholder has its own interest and seeks to achieve different objectives with the urban water system. Whereas shopkeepers in the city center would put budgetary priority at flood prevention measures, environmental groups would prioritize investments towards water quality improvements. And utility customers may primarily be concerned with costs. There is therefore a natural link between systems engineering and Triple Bottom Line assessment (Kenway et al. 2007). The objectives for which the system is designed will always include social, environmental and economic aspects.

Apart from professionals that are needed to design and run the elements of the system, there is also a need for urban water managers that are capable to maintain a 'helicopter view' on the entire system. The urban water manager is like a systems engineer who requires sufficient knowledge on all elements, so that he or she is able to coordinate detailed investigations. Moreover, the urban water manager needs to evaluate whether the Triple Bottom Line (TBL; economy, society, environment) is sufficiently addressed in all planning and decision making.

\section{System design, strategy development and strategic urban planning}

SWITCH is aimed at the 'city of the future'. Therefore it includes a certain extent of re-design of the urban area in order to achieve the sustainability objectives. The emphasis is on developing strategies for the system as a whole. Its focus is on the development of an overall strategy and the translation of this into 'strategic planning'. A strategy has been defined as "A framework guiding those choices that determine the nature and direction to attain the objective" (Saunier and Meganck 2004). Strategic 
planning is therefore the description of the major choices and what these choices mean for the city. And it is fed by data on the urban water system.

The SWITCH strategic planning methodology was adapted from the EMPOWER project (Batchelor and Butterworth 2008) and Foxon et al. (2002). The different steps in this planning process are indicated in Fig. 2. Key elements are:

\subsection{Visioning and sustainability objectives}

A vision is "a concise description of a desired future. Visions provide a picture of how we would like the world (or our water resources and services) to be at some agreed future time" (Batchelor and Butterworth 2008). The next step in the process is that the vision is translated in a set of SMART objectives. We may

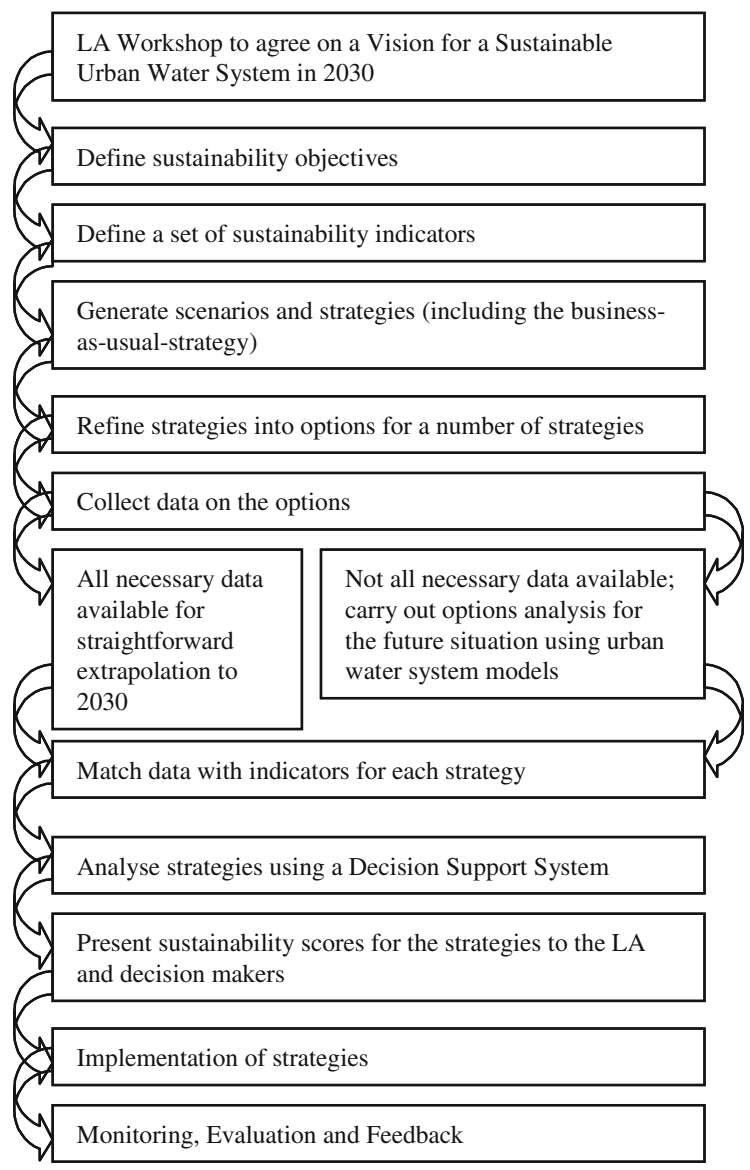

Fig. 2 The role of sustainability indicators in strategic planning of the urban water system. (Adapted from Foxon et al. 2002) call these objectives 'sustainability objectives', since the overall aim is to reach a sustainable urban water system. Once the objectives have been agreed by the Learning Alliance, we could formulate one or more sustainability indicator for each sustainability objective.

\subsection{Scenario development}

After the vision and the set of sustainability indicators has been agreed, the Learning Alliance's will formulate a number of possible future scenarios. "Scenarios are stories about the way the world might turn out tomorrow. A scenario is a consistent description of a possible future situation as determined by those factors that are both most important and most uncertain" (Batchelor and Butterworth 2008).

\subsection{Strategy development}

Subsequently, the Learning Alliance will work out different strategies that are aimed to reach the vision under the conditions of a certain scenario. The scenarios and strategies that are being developed in workshops in the cities are at first instance to a large extent qualitative, without a data-based and in depth analysis. This in-depth analysis, using research and demonstration results of the SWITCH project, are added during the next stage. Finally, a City Strategy, based on solid data and in depth analysis will be agreed and adopted during a final workshop on the "City Strategy for 2030". Although the strategy development is presented here as a linear process, in reality its nature is much more cyclic. After every step in the process the planners need to check previous steps. Is the vision still the same and still achievable? Have scenarios changed, for instance due to the availability of new data? Have new strategies emerged, for instance due to the development of new technologies?

\section{Sustainability indicators (SIs)}

Sustainability indicators can be used by cities to monitor the cities progress towards sustainability. Indicators are pieces of information, which summarize important properties, visualize phenomena 
of interest, quantify trends and communicate them to relevant target groups (Lundin and Morisson 2002). They are useful tools in decision making when they (a) provide information for spatial comparison, (b) provide early warning information and (c) anticipate future conditions and trends. A city that is going through a process of re-designing or developing its urban water system for the future, obviously would like to know where it is going. Is it getting nearer to sustainability or not? However, one has to recognize that sustainability cannot be measured in absolute terms, such as the $\mathrm{pH}$ of a water sample. Sustainability is in fact defined by the stakeholders, that give different weights to different TBL aspects.

In a strategic planning process, SIs can be used to measure to what extent the sustainability objectives have been achieved. Since the idea is that the sustainability objectives are developed jointly with all stakeholders, one may assume that the set of sustainability indicators are also agreed by the stakeholders. The coordinating institution for urban water management is supposed to coordinate a process by which the data to score the indicators is collected. The result for the different indicators is then used (typically) once per year or once per 2 years. The score of the indicators is used to evaluate whether the cities strategies, policies and projects are effective in reaching the objectives. If it is noticed that the city is moving away for some indicators from sustainability, the strategies need to be adjusted (Fig. 3).

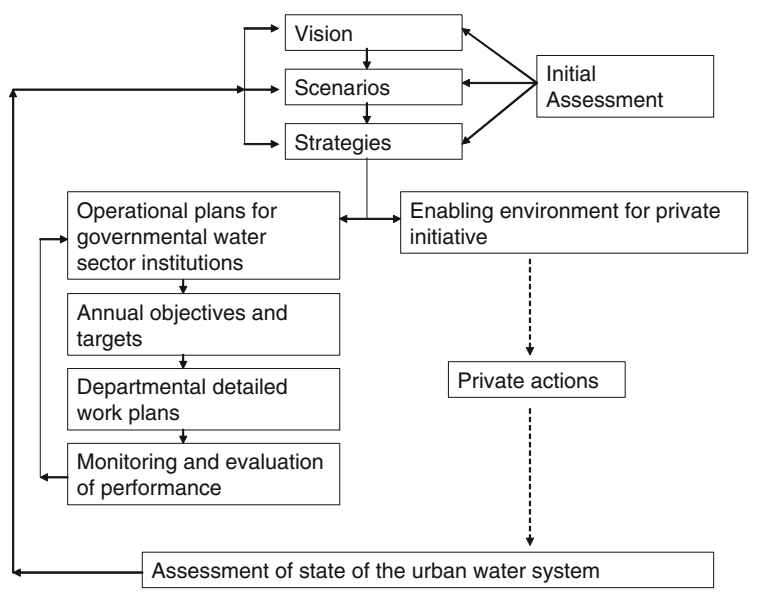

Fig. 3 Implementation phase of the strategic planning process
Some indicators are simple to measure, such as the drinking water quality. Other indicators are aggregate indicators and need certain assessment tools to be scored. Such assessment tools include cost-benefit analysis, functional risk analysis, microbial risk analysis, life-cycle assessment, sensitivity analysis, material flow analysis, behaviour/attitude investigations based on interviews and action research (Hellström et al. 2000), various financial assessments, embodied energy assessment, ecological footprint and multi criteria assessment (see Kenway et al. 2007 for overview).

\section{Evaluation of integrated assessment methods}

Case studies have shown that extensive data sets are required for a proper integrated assessment of the urban water system and that in none of the cities all required data is readily available. Therefore assumptions had to be made that introduced large uncertainties in some of the analysis. Cities need to invest more in collection, archiving and making this kind of datasets accessible. The lack of data and the dispersion of data over many institutions is not only the case in developing countries but also in Europe. In fact this is not surprising, since this type of integrated assessment is cross-cutting, and cuts through traditional system and institutional boundaries. The lack of data and the need for assumptions introduced uncertainty. On-going work on risk assessment and decision making will give more insight whether this uncertainty will or will not prevent this approach to be used for strategic decision making.

The integrated assessment methods (especially the Life Cycle Analysis and Quantitative Microbial Risk Assessment) require specialist knowledge to be fully understood. The complexity of systems analyis and the assessment methods, makes them not directly suitable to be used in strategic planning. It is suggested that these methods are used to score indicators, that decision makers and urban planners feel comfortable with. The link between these methods and the indicators strengthen the scientific basis under the use of indicators. In that sense this suggestion is an improvement to the current situation, in some cities, where indicators are selected rather haphazard and without scientific basis. 


\section{Conclusions}

The studies on the application of systems analyis, systems engineering, Life Cycle Analysis and Quantitative Microbial Risk Assessment in SWITCH demonstration cities show that an integrated analysis and design of the urban water system is possible. The tools for analysis are available and within a relatively short period, a general picture of the urban water system can be created and the effect of different strategies can be evaluated. However, two major challenges remain. Firstly, to overcome the lack of sufficient data (availability and accessibility) to do more detailed integrated assessments. Secondly, the results of the assessments can only be used for decision making and strategic planning after the results have been translated into a limited number of relatively simple indicators. Further research will focuss on the translation of the results from integrated assessment methods into sustainability indicators that are feasible for use in strategic planning.

In the next SWITCH Monitors in this journal experiences with the use of scientific information in strategic urban planning of the water system will be presented.

\section{References}

Batchelor C, Butterworth J (2008) Scenario building. SWITCH learning alliance briefing Note 11. http://www.switchur banwater.eu/outputs/results.php?wp_select=17\&pubtype_ select=1\&op2_select=\&pt=Learning\%20Alliance $\% 20$ Briefing\%20Notes\&m=0,6,1,1 [Accessed March 2009]

Foxon TJ, McIlkenny G, Gilmour D, Oltean-Dumbrava C, Souter N, Ashley R, Butler D, Pearson P, Jowitt P, Moir J (2002) Sustainability criteria for decision support in the UK water industry. J Environ Plan Manag 45(2):285-301

Hellström D, Jeppsson U, Kärrman E (2000) A framework for systems analysis of sustainable urban water management. Environ Impact Assess Rev 20:311-321. doi: 10.1016/S0195-9255(00)00043-3

Kenway S, Howe C, Maheepala S (2007) Triple bottom line reporting of sustainable water utility performance. Awwa Research Foundation, CSIRO, IWA publishing, p 147

Lundin M, Morisson GM (2002) A life cycle assessment based procedure for development of environmental sustainability indicators for urban water systems. Urban Water 4:145-152

Mitchell VG (2004) Integrated Urban water management. A review of Australian practice. CSIRO and AWA report CMIT-2004-075, pp 56

Saunier RE, Meganck RA (2004) C.H.A.O.S.S. An essay and glossary for students and practitioners of global environmental governance. Balkema Publishers, The Netherlands

Smith AA, Hinton E, Lewis RW (1987) Civil engineering systems. Analysis and design

UNESCO (2007) Paris statement on Urban water management. http://www.unesco.org/water/ihp/pdf/uwm_statement_2007. pdf [Accessed March 2009] 